\title{
INEQUALITIES FOR THE JACOBIAN ELLIPTIC FUNCTIONS WITH COMPLEX MODULUS
}

\section{KLAUS SCHIEFERMAYR}

Abstract. Despite the fact that there is a huge amount on papers and books devoted to the theory of Jacobian elliptic functions, very little is known when the modulus $k$ of these functions lies outside the unit interval $[0,1]$. In this note, we prove some simple inequalities for the absolute value of Jacobian elliptic functions with complex modulus.

Mathematics subject classification (2010): 33E05.

Keywords and phrases: Inequality, Jacobian elliptic function.

\section{REFERENCES}

[1] P. F. BYRD AND M. D. Friedman, Handbook of elliptic integrals for engineers and scientists, Springer, 1971.

[2] D. F. LAwDEn, Elliptic functions and applications, Springer, New York, 1989.

[3] F. W. J. Olver, D. W. LOZier, R. F. Boisvert, AND C. W. Clark (eds.), NIST handbook of mathematical functions, U. S. Department of Commerce National Institute of Standards and Technology, Washington, DC, 2010.

[4] P. WALKeR, The analyticity of Jacobian functions with respect to the parameter $k, \mathrm{R}$. Soc. Lond. Proc. Ser. A Math. Phys. Eng. Sci. 459 (2003), 2569-2574.

[5] P. L. WALKeR, The distribution of the zeros of Jacobian elliptic functions with respect to the parameter $k$, Comput. Methods Funct. Theory 9 (2009), 579-591.

[6] E. T. Whittaker And G. N. Watson, A course of modern analysis, Cambridge University Press, New York, 1962. 